\title{
Production of biochar from biomass
}

Iqmat Iyiola ${ }^{1}$, Deepak Pudasainee ${ }^{1}$, Md Khan $^{1}$, Rajender Gupta ${ }^{1}$

${ }^{1}$ Department Chemical and Materials Engineering, University of Alberta

\begin{abstract}
Biochar is a kind of charcoal that's produced from biomass using pyrolysis technology. As climate change continues to be a growing concern, biochar has been sought for its environmental applications. It is both cost effective and environmentally sound in terms of being a soil additive and renewable fuel. When used as a soil amendment, biochar has been shown to improve water holding capacity and absorb more nutrients. Biochar also sequesters carbon dioxide when applied to soil, and can also be used as a replacement for activated carbon that is prepared from coal. The objectives of this research was to produce biochar from biomass and study biochar's properties. A thermogravimetric analysis (TGA) was used to measure the weight loss behavior of the wood sample (biomass) as the temperature increased. The biomass was heated to $500{ }^{\circ} \mathrm{C}$ in a nitrogen atmosphere and then cooled in nitrogen to prevent combustion of biochar. The overall yield of biochar was $15 \%$. Elemental analysis of biomass shows the composition of the sample to be mostly carbon and oxygen with fewer amounts of hydrogen and nitrogen. Surface area of the prepared biochar was 305 $\mathrm{m} 2 / \mathrm{g}$, which is approximately 100 times the surface area of raw biomass. Biochar's higher porosity will allow for greater absorption of nutrients when applied to soil.
\end{abstract}

Key words:

biomass, biochar, TGA, proximate analysis, elemental analysis, chemical engineering

Cite as: Iyiola I., Pudasainee D., Khan M., and Gupta R. 2019. Production of biochar from biomass. Alberta Academic Review, Vol 2 (2) 43-44, WISEST Special Issue (not peerreviewed), DOI 10.29173/aar50. 
lyiola et al., 2019

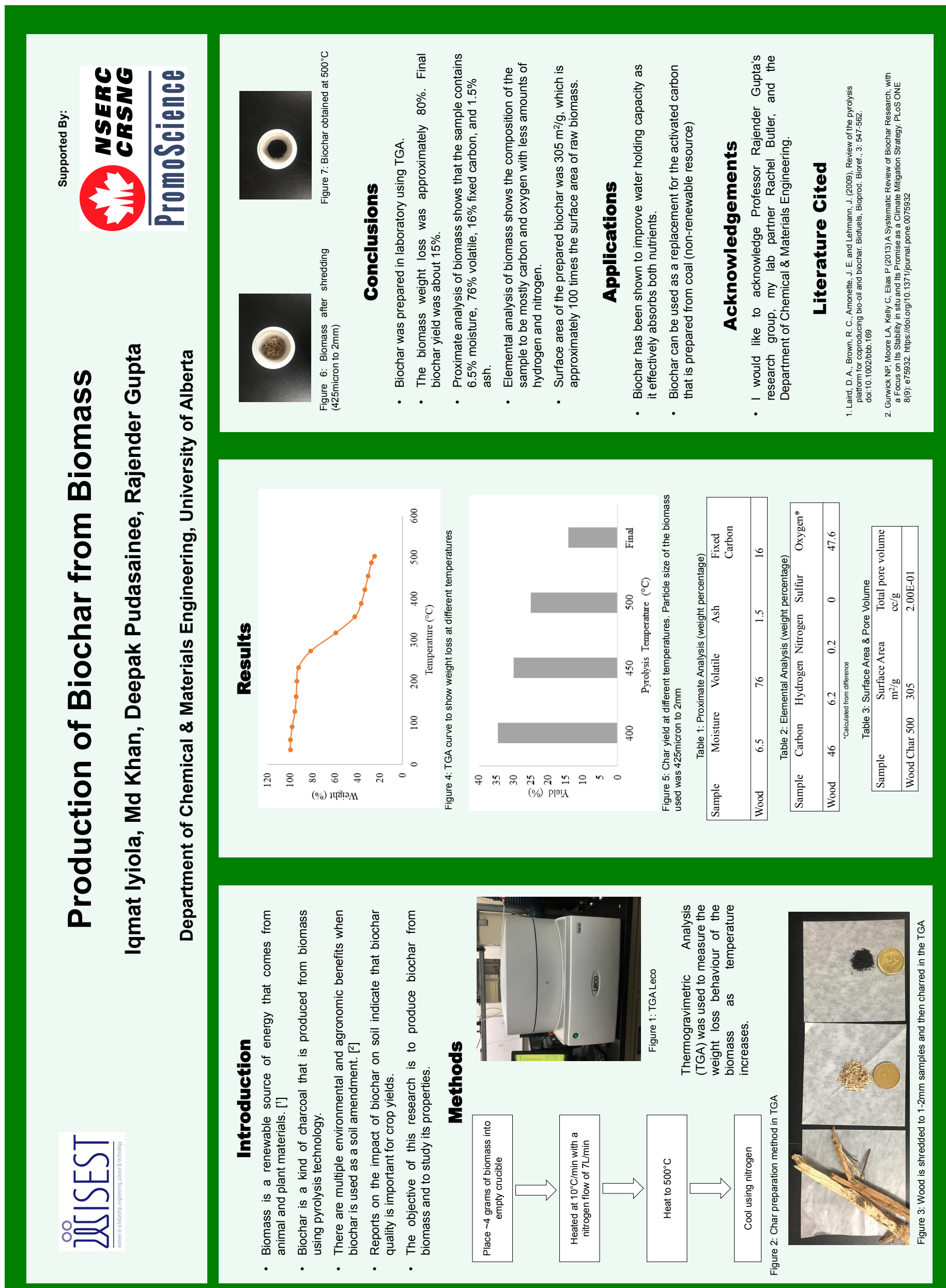

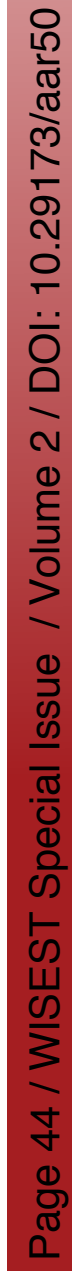

